\title{
Threat of pain influences social context effects on verbal pain report and facial expression.
}

Citation for published version (APA):

Vlaeyen, J. W. S., Hanssen, M., Goubert, L., Vervoort, T., Peters, M. L., van Breukelen, G. J. P., Sullivan, M., \& Morley, S. J. (2009). Threat of pain influences social context effects on verbal pain report and facial expression. Behaviour Research and Therapy, 47(9), 774-782. https://doi.org/10.1016/j.brat.2009.05.008

Document status and date:

Published: 01/01/2009

DOI:

10.1016/j.brat.2009.05.008

Document Version:

Publisher's PDF, also known as Version of record

Document license:

Taverne

Please check the document version of this publication:

- A submitted manuscript is the version of the article upon submission and before peer-review. There can be important differences between the submitted version and the official published version of record.

People interested in the research are advised to contact the author for the final version of the publication, or visit the DOI to the publisher's website.

- The final author version and the galley proof are versions of the publication after peer review.

- The final published version features the final layout of the paper including the volume, issue and page numbers.

Link to publication

\footnotetext{
General rights rights.

- You may freely distribute the URL identifying the publication in the public portal. please follow below link for the End User Agreement:

www.umlib.nl/taverne-license

Take down policy

If you believe that this document breaches copyright please contact us at:

repository@maastrichtuniversity.nl

providing details and we will investigate your claim.
}

Copyright and moral rights for the publications made accessible in the public portal are retained by the authors and/or other copyright owners and it is a condition of accessing publications that users recognise and abide by the legal requirements associated with these

- Users may download and print one copy of any publication from the public portal for the purpose of private study or research.

- You may not further distribute the material or use it for any profit-making activity or commercial gain

If the publication is distributed under the terms of Article $25 \mathrm{fa}$ of the Dutch Copyright Act, indicated by the "Taverne" license above, 


\title{
Threat of pain influences social context effects on verbal pain report and facial expression
}

\author{
Johan W.S. Vlaeyen ${ }^{\mathrm{a}, \mathrm{b}, *}$, Marjolein Hanssen ${ }^{\mathrm{b}}$, Liesbet Goubert ${ }^{\mathrm{c}}$, Tine Vervoort ${ }^{\mathrm{c}}$, Madelon Peters ${ }^{\mathrm{b}}$, \\ Gerard van Breukelen ${ }^{d}$, Michael J.L. Sullivan ${ }^{\mathrm{e}}$, Stephen Morley ${ }^{\mathrm{f}}$ \\ a Department of Psychology, Research Group Health Psychology, University of Leuven, Belgium \\ ${ }^{\mathrm{b}}$ Department Clinical Psychological Science, Maastricht University, Netherlands \\ ${ }^{\mathrm{c}}$ Department of Experimental-Clinical and Health Psychology, Ghent University, Belgium \\ ${ }^{\mathrm{d}}$ Department of Methodology and Statistics, Maastricht University, Netherlands \\ ${ }^{\mathrm{e}}$ Department of Psychology, McGill University, Canada \\ ${ }^{\mathrm{f}}$ Institute of Health Sciences, University of Leeds, United Kingdom
}

\section{A R T I C L E I N F O}

\section{Article history:}

Received 31 October 2008

Received in revised form

27 May 2009

Accepted 29 May 2009

\section{Keywords:}

Pain behavior

Pain catastrophizing

Threat of pain

Safety behaviors social context

Communal coping model

Cognitive appraisal model

\begin{abstract}
A B S T R A C T
Current theoretical models of pain catastrophizing have diverging predictions regarding the role of social context and perceived threat on pain expression. The communal coping model of catastrophizing predicts that high pain catastrophizers display more pain expression in the presence of another, regardless of the threat value of the pain, while a cognitive appraisal model predicts high pain catastrophizers to express more pain when pain has increased threat value, regardless of social context. A $2 \times 2$ factorial design was used to test the validity of both predictions. Healthy participants with varying levels of pain catastrophizing were exposed to a cold pressor task, consisting of a $60 \mathrm{~s}$ immersion and $60 \mathrm{~s}$ recovery period. Interestingly, the immersion results revealed that beyond and independent from the effects of pain catastrophizing, the effect of threat on verbal pain report and facial expression was dependent on social context and vice versa. In a threatening context, perceived threat of pain mediated the inhibitory effect of social presence on pain expression, suggesting that the observer acted as a safety signal. In the recovery period, social presence enhanced facial expression, but only when no threat was induced. The results are discussed in terms of the dynamic interaction between social context and threat appraisals.
\end{abstract}

(c) 2009 Elsevier Ltd. All rights reserved.

\section{Introduction}

Pain is a universal experience that affects human beings across the life span, and serves an important protective function. Pain urges to interrupt ongoing activity, to escape the source of threat to the body, and to withdraw for healing to take place (Eccleston \& Crombez, 1999).

Over the past decade, there has been increasing interest in questions concerning the influence of social context on the experience of pain and associated pain behavior (Keefe \& Porter, 2007; Tait, 2007). Traditionally, the role of social context was framed in social modeling (Craig, 1978) and operant conditioning processes (Fordyce, 1976). Indeed, important others have been shown to influence the experience of pain and how pain is expressed (Craig,

\footnotetext{
* Corresponding author. Department of Psychology, Research Group Health Psychology, University of Leuven, Tiensestraat 102, 3000 Leuven, Belgium. Tel.: +32 16 325915; fax: +32 16325923

E-mail address: johan.vlaeyen@psy.kuleuven.be (J.W.S. Vlaeyen).
}

1975; Hadjistavropoulos \& Craig, 2002; Turkat \& Guise, 1983). These studies seem to suggest that punishing responses are associated with inhibited expression of verbal and non-verbal pain behavior, while empathic responses are associated with behaviors of greater magnitude (Flor, Knost, \& Birbaumer, 2002; Jolliffe \& Nicholas, 2004; Lousberg, Schmidt, \& Groenman, 1992).

More recently, individual differences in the way how pain is catastrophically interpreted have also been examined in a social context of a refined communal coping model (CCM) (Lackner \& Gurtman, 2004; Sullivan et al., 2001; Thorn, Ward, Sullivan, \& Boothby, 2003). Pain catastrophizing has been conceptualized as a way of eliciting empathic responses from others (Sullivan, Adams, \& Sullivan, 2004; Sullivan et al., 2001; Thorn, Keefe, \& Anderson, 2004; Thorn et al., 2003). The CCM predicts that high pain catastrophizers will express pain in especially in the presence of others, because they feel vulnerable and feel the need to seek support from others through the expression of pain.

Evidence for the CCM is provided by Sullivan et al. (2004) who showed that during a cold pressor task, healthy subjects scoring 
high on pain catastrophizing displayed more pain expression in the presence of a neutral observer as compared those who performed the task alone. For the low pain catastrophizers, social context did not affect their pain expression during the pain task. Using a similar experimental pain task, Vervoort and colleagues found children high in pain catastrophizing displayed equal amounts of pain behavior in the presence of both of their parent and a stranger. Their low catastrophizing counterpart, however, were found to express significantly less pain in the presence of a stranger as compared to the presence of own their parent (Vervoort et al., 2008).

Of interest, however, is that studies finding support for CCM have not varied the threat value of the noxious stimulus. Indeed, a number of investigations have shown that threatening information about pain influences pain intensity and pain tolerance (Arntz \& Claassens, 2004; Jackson et al., 2005; Vlaeyen, Kole-Snijders, Boeren, \& van Eek, 1995). The central thesis of a cognitive appraisal model (CAM) is that idiosyncratic interpretation of a stimulus determines how strongly it is perceived, and which affect it elicits. The CAM assumes that individuals who catastrophize about pain habitually assign increased threat value to innocuous stimuli, thereby experiencing increased pain-related fear. There is accumulating evidence that catastrophic interpretations of pain produce increased pain-related fear and associated escape, avoidance and safety seeking behaviors, both in experimental and clinical settings (Lethem, Slade, Troup, \& Bentley, 1983), for a review, see (Vlaeyen \& Linton, 2000).

Although the role of the social context is not specified in the CAM it is arguable that certain social contexts might represent safety cues that signal to the individual that imminent threat will be reduced (e.g. (Lohr, Olatunji, \& Sawchuk, 2007; Tang et al., 2007)). To our knowledge, no studies exist that have manipulated both the threat value of the pain as well as the social presence during a pain task in one single experiment. Manipulations of threat and social presence afford an interesting opportunity to examine competing predictions of CCM and CAM, and to elucidate the relative contribution of the threat value of pain and the presence of a neutral observer in subjects with varying levels of pain catastrophizing. Because both models are not specified in terms of the dependent variable, we decided to include a verbal and nonverbal measure of pain expression in the current study. This is also in line with the recommendation to use both kinds of measures in the assessment of pain because of their unique informational value (Hadjistavropoulos \& Craig, 2002). A comparison of CCM and CAM models of pain catastrophizing is not only of theoretical importance, but also has potential clinical implications as tailored and specific treatment of patients who score high on pain catastrophizing are scarce (Thorn, Boothby, \& Sullivan, 2002; Thorn et al., 2007). Additionally, current exposure-based treatments for patients with increased pain-related fear have not explicitly addressed the involvement of the social context (Leeuw et al., 2008; Vlaeyen, de Jong, Geilen, Heuts, \& van Breukelen, 2001).

\section{Methods}

\section{Design}

We have chosen a design that allows testing the predictions based on the CCM as well as those based on the CAM. High and low pain catastrophizing healthy subjects were exposed to a cold pressor task in a $2 \times 2$ factorial design in which both threat of pain (THREAT) and social context (SOCIAL) were experimentally manipulated. Participants were exposed to the pain stimulus for $60 \mathrm{~s}$, followed by a $60 \mathrm{~s}$ recovery period. Perceived threat of the cold pressor task was assessed at baseline, after the THREAT manipulation and after the immersion. Pain catastrophizing was dichotomized for the purpose of pre-stratification in the random assignment procedure, but kept continuous when used as covariate in the analyses. Dependent variables were pain report using numerical rating scales and facial expression using a standardized observational coding system. Threat of pain was manipulated using the verbal instruction that "Exposure to ice cold water can lead to freezing in the long term" in combination with "Your blood pressure is rather high but just within the limits to allow participation to the cold water procedure". This manipulation was successfully used previously (Van Damme, Crombez, Van Nieuwenborgh-De Wever, \& Goubert, 2008).

The hypothesis based on the CCM was that high pain catastrophizers would report more pain and display more facial expression of pain in the presence of an observer compared to those who were alone during the pain procedure, irrespective of the threat value of the pain. Hence, we expected a statistical SOCIAL*Pain catastrophizing interaction, as previously found by Sullivan and colleagues (Sullivan et al., 2004). In contrast, the hypothesis based on CAM was that high pain catastrophizers would express more pain, and that this effect is amplified when pain is perceived as threatening, compared to high pain catastrophizers who are faced with pain that is less threatening, irrespective of the presence of an observer. Therefore we expected a statistical THREAT*Pain catastrophizing interaction. As an additional test of CAM, we also examined whether any inhibitory 'safety' effects of social presence on pain expression were indeed mediated by changes in perceived threat of pain.

\section{Participants}

From a sample of 224 students and staff who responded favorably to advertisements that were posted at different campus sites of Maastricht University, 152 met the selection criteria and agreed to participate in the experiment. A screening procedure was used to exclude participants who had a medical condition that might be adversely affected by the cold pressor task procedure, and participants who were reporting current pain or a chronic pain condition. Five participants did not complete the cold pressor task and removed their hand before the end of the $60 \mathrm{~s}$ immersion time. For three of these participants whose immersion time exceeded $40 \mathrm{~s}$, the missing $60 \mathrm{~s}$ pain rating was replaced by the previous (40 s) pain rating. Two participants withdrew their hand before the $40 \mathrm{~s}$ pain rating, and their data were excluded for further analyses, as well as the data of another participant who failed to complete one of the questionnaires. The final sample of 149 participants consisted of 61 men and 88 women, with a mean age of 33.3 years $(\mathrm{SD}=9.3)$ and 29.6 years $(\mathrm{SD}=11.3)$ respectively. It can be shown that for the present $2 \times 2$ between subject design this $N$ is sufficient to detect a medium effect (main or interaction) size $d=.50$ with power $=.80$ using alpha $=.05$ two-tailed. Participants were randomized into one of four conditions: No threat/no observer $(N=39)$, no threat/observer present $(N=37)$, threat/no observer $(N=35)$, threat/observer present $(N=38)$. Pre-stratification on pain catastrophizing and gender was used to ensure equal levels of pain catastrophizing and gender distributions in all 4 groups. A total score on the Pain Catastrophizing Scale of 16 was used for stratification in high and low catastrophizers (Van Damme, Crombez, Bijttebier, Goubert, \& Van Houdenhove, 2002).

\section{Apparatus}

The cold pressor task consisted of a refrigerated unit (30-50$30 \mathrm{~cm}$ ) that maintained circulating water ranging between $2^{\circ}$ and 
$4^{\circ}$ Celsius. Participants were requested to hold their arm in the CPT tank for exactly $60 \mathrm{~s}$. Prior to the task, participants were requested to immerse their hand in a unit that contained water at room temperature $\left(20^{\circ}\right.$ Celsius). The immersion period was followed by a recovery period of $60 \mathrm{~s}$. A computer was available in the room for the electronic administration of questionnaires. Each participant was videotaped, using two digital video cameras that were placed concealed in the room. One camera was used for a whole body recording, while the other camera recorded facial expression only. For the current study, only the data of the facial expression recordings were used.

\section{Measures}

\section{Threat manipulation check}

In order to check whether our threat manipulation worked as intended, two series of statements were developed reflecting the perceived threat of pain (PTP), related to the cold pressor task, each followed by an 11-point rating scale. One series was taken just before (PTP1) and just after the threatening information (PTP2), and the other series after the post-immersion recovery period (PTP3). Because the reversed scored items compromised the internal consistency they were excluded. Typical PTP1-2 items were "I wonder whether this test can be harmful for my hand", and "I worry that something serious can happen". For PTP3, the items were put in the past tense. A total score was calculated as the sum of the 8 remaining items, divided by 8 (theoretical range $=0-11$ ). Cronbach's Alpha was .76, .83 and .79 for the three versions respectively, indicating good internal consistency. Correlations between PTP1 and PTP2 for each condition separately were high (Pearson rho ranging between .87 and $.93, p<.001$ ) suggesting good stability. The correlations between PTP3 and the other versions were lower, but still significant (for PTP1: Pearson rho ranging between $r=.37$ and .73, highest $p=.02$; and for PTP2: Pearson rho ranging between $r=.33$ and .85 , highest $p=.04$ )

\section{Pain catastrophizing}

Pain-related catastrophizing was measured with the Dutch version of the Pain Catastrophizing Scale (Van Damme et al., 2002). The 13 items were rated on a 5-point scale to describe the frequency with which participants experienced different thoughts and feelings associated with pain, and each item belongs to one of three subscale: rumination, magnification and helplessness (Sullivan, Bishop, \& Pivik, 1995). Only PCS total scores were used in this study (theoretical range $=0-52$ ). The PCS was administered twice, first during the screening period for stratification purposes, and secondly also prior to threat manipulation and the immersion. Cronbach's Alpha was .90 and equal for both administrations, indicating high internal consistency. Total scores of both PCS administrations correlated highly (Pearson $r=.84, p<.01$ ).

\section{Verbal pain report}

Pain intensity was measured with an 11-point numerical rating scale. Participants were prompted by a tape recorded tone to verbally rate their pain intensity at $20 \mathrm{~s}, 40 \mathrm{~s}$ and $60 \mathrm{~s}$ after immersion, and at 30 and $60 \mathrm{~s}$ of the $1 \mathrm{~min}$ recovery period. The rating scale was placed in front of the participant in the form of a thermometer anchored with the 'no pain at all' $(0)$ and 'worst pain ever experienced' (10). An average of the three ratings of pain during the immersion, and the two ratings during recovery were used for further analyses.

\section{Facial expression}

Video-recorded facial expressions were assessed with the Child Facial Coding System (CFCS; (Chambers, Cassidy, McGrath, Gilbert,
\& Craig, 1996)), a coding system derived from the Facial Action Coding System (Ekman \& Rosenberg, 1997). The CFCS distinguishes 13 different facial actions typical of pain expression (Brow lowering, squint, eye squeeze, nose wrinkle, nasolabial furrow, cheek raiser, upper lip raise, lip corner pull, vertical mouth stretch, horizontal mouth stretch, blink, flared nostril and open lips) and can also be used in adults. Coding was done by two independent research assistants who were blind to the participant's level of experienced pain and the experimental condition for each consecutive $10 \mathrm{~s}$ segments: 6 segments during immersion, 6 segments recovery. For each second, 10 facial actions were coded for intensity (no action (0), slight action (1), distinct/maximal action (2)), and 3 facial actions (blink, flared nostril, open lips) were coded as absent or present ( 0 or 1 ). Inter-rater agreement was computed by having the second rater score $20 \%$ of the video segments of the first coder. Reliability was calculated according to the formula given by Ekman and Friesen (1978), which assesses the proportion of agreement on actions recorded by two coders relative to the total number of actions coded as occurring by each coder. Inter-rater reliability between both coders was 69\% (with intensity) and $77 \%$ (without intensity) respectively. A total score of all coded facial action was calculated for each period (immersion and recovery).

\section{Procedure}

Subjects who responded via e-mail to flyers and advertisements that were disseminated around the Maastricht University campus were sent a package including a letter providing general information about the study, a screening questionnaire regarding demographics (age and gender) as well as their health status for selection purposes, and a version of the PCS for stratification. Subjects who still wanted to participate were invited to send the completed questionnaires by mail using the pre-stamped envelope. At arrival in the lab, participants received verbal information about the experiment, were asked to sign the informed consent form, and to complete the PCS for the second time, a VAS assessing their current pain (if applicable), and the perceived threat measure (PTP1). Subsequently, randomization over the 4 conditions took place with pre-stratification on gender and PCS scores using total cut-off score of 16. This cut score was selected on the basis of a previous study which sampled from this population in which 16 was identified as the median value (Van Damme et al., 2002). Participants were then asked to immerse their arm in a container with water at room temperature for the duration of $5 \mathrm{~min}$, in order to establish equal baseline skin temperatures. During this first immersion participants were told that the researcher would soon leave the room, and that they were to listen to a tape recording with subsequent instructions about the CPT. They were told that a brief tone would indicate that they could report their pain intensity level by saying out loud a number between 0 and 10, using the pain thermometer that was placed in front of the participant. At this point the social presence and threat manipulations took place (see below.) After these instructions, and just before the immersion as well as immediately after the one-minute post-immersion period, participants were asked to complete the threat manipulation measure again. After the recovery period, participants were debriefed, thanked and given a traveling allowance and a gift coupon of 5 Euro as a token of appreciation.

\section{Social presence}

Participants who were allocated to the conditions with social presence were led to believe that a trainee from another university was being given the opportunity to observe a CPT procedure in the context of her masters' thesis. During the room temperature 
immersion, the experimenter also asked the participant whether he or she would agree to have the trainee observe the session. All participants agreed. Once she entered the lab, the female trainee (one of two female research assistants) introduced herself to the participant, took place on a chair in front of the participant, and asked the researcher a number of questions about the CPT procedure. The latter was done to increase the credibility of the observer as a trainee. During the immersion and recovery periods, the observer did not engage in attempts to communicate with the participants, and responded with brief yes/no answers or just nodding in response to attempts of the participants to communicate with her

\section{Threat manipulation}

In the threat conditions, threat was induced similar to the procedures used in previous studies (Jackson et al., 2005; Van Damme et al., 2008). Blood pressure was measured twice, and a false pressure value was reported, indicating that it was at borderline acceptability for safe CPT participation. In addition, normal CPT effects such as skin color changes and tingling sensations were labeled as the first symptoms of frostbite. In the neutral conditions, no blood pressure was measured and participants were told that the skin color changes and tingling sensation were normal and benign. ${ }^{1}$

\section{Statistical analyses}

The threat manipulation check and effects of the experimental manipulations of perceived threat were analyzed with univariate ANCOVA. Age, Gender, Pain catastrophizing (measured with second assessment of PCS, just before the experimental manipulations) were always included as covariates in their centered form. Effects of the experimental manipulations on verbal pain report and facial expression were first analyzed with split plot repeated measures ANCOVAs with THREAT information (yes/no), SOCIAL presence (yes/no) as fixed between subject factors, and TIME (immersion vs. recovery) as a within subject factor. Pain catastrophizing was included as a continuous measure and its interactions with fixed factors THREAT and SOCIAL presence were calculated. In case of any significant interaction between TIME and one or both between subject factors, analyses for immersion and recovery data were carried out separately. For these analyses, only the three-way and two-way interactions among Pain catastrophizing, THREAT and SOCIAL were tested. Again, Age, Gender, and Pain catastrophizing were always included as covariates. Non-significant interactions $(p>.05)$ were deleted from the model one by one, starting with the three-way interaction, followed by the two-way interactions and main effects. If a significant interaction between both factors was found, ANCOVA's were run per level of one factor to evaluate the effect of the other factor and vice versa, with the same covariates as before. Results of the final models are presented here. Effect sizes for simple effects were calculated with Cohen's $d$ (=mean difference divided by the root of the mean square residual of the final model including all covariates). As a further test of CAM, the mediating role of perceived threat (as measured after the threat manipulation, PTP2) in the association between threat information and social presence on the one hand and verbal pain report and facial expression on the other were examined. Therefore, regression analyses were performed following standard procedures (Baron \& Kenny, 1986; MacKinnon, Lockwood, Hoffman, West, \& Sheets, 2002). As the Sobel test may suffer from lower power, the criterion proposed by MacKinnon et al. (2002) was used (joint

\footnotetext{
${ }^{1}$ Verbatim instructions can be obtained from the first or second author.
}

significance of paths a (independent $\rightarrow$ mediator) and b (mediator $\rightarrow$ dependent)).

\section{Results}

Threat manipulation check. Table 1 reports the descriptive statistics for the main variables by group. Means of the perceived threat scores for the four conditions at baseline, after threat manipulation and before immersion, and just after immersion, are displayed in Fig. 1. ANCOVA with the perceived threat measure after the threat induction prior to immersion (PTP2) as dependent variable, THREAT information and SOCIAL presence as independent variables, and baseline perceived threat (PTP1), age, gender, and pain catastrophizing as covariates revealed a significant main effect for THREAT, $F(1,141)=18.47, p<.001$, baseline perceived threat of pain $F(1,141)=402.79, p<.001$, suggesting that subjects who received the threatening information felt more concerned about imminent cold pressor task procedure than subjects who did not receive threatening information (mean change for threat conditions $=.32$, $\mathrm{SD}=.65$; mean change for neutral conditions $=.-.18, \mathrm{SD}=.62$ ). In addition, pain catastrophizing also independently predicted perceived threat of the pain task, $F(1,141)=4.44, p=.037$.

Perceived threat. A similar analysis was performed to examine whether the presence of an observer during the cold pressor task affected the perceived threat of the pain stimulus. ANCOVA with the threat manipulation measure PTP3 as the dependent variable, and PTP1 as a covariate together with age, gender, and pain catastrophizing, this time revealed a significant effect of SOCIAL presence, $F(1,141)=3.885, p=.051$, in addition to PTP1, $F(1$, $141)=24.187, p<.001$ and pain catastrophizing, $F(1,141)=15.826$, $p<.001$. None of the interaction terms reached significance and these were removed from the model before testing the main effects reported here. As displayed in Fig. 1, participants who performed the cold pressor task with an observer present felt less concerned about the pain task as compared to those who did the task alone. Apparently, the observer acted as a safety cue, reducing their concern about the effects of the pain stimulus, regardless of whether threat information was provided or not.

Verbal pain ratings. Means of the pain intensity scores across the four conditions are displayed in Fig. 2. These suggest that during immersion, subjects in the condition with threatening information but without an observer experienced more pain than those in the other three conditions. There was no significant three-way TIME*THREAT*SOCIAL interaction, $F(1,141)=1.157$, NS, nor a twoway TIME*SOCIAL, $F(1,141)=1.597$, NS. A significant TIME*THREAT interaction, $F(1,141)=4.395 ; p=.038$ suggests that the influence of THREAT on pain report during the immersion was different from that in the recovery period. Therefore, separate ANCOVA's were performed for each period.

Immersion. No significant three-way 'THREAT*SOCIAL*Pain catastrophizing' interaction was found, $F(1,138)=.02$, NS, and neither the predicted two-way interactions 'Pain catastrophizing*THREAT' $F(9,138)=.003$, NS, and 'Pain catastrophizing*'SOCIAL', $F(1,138)=.230$, NS, were significant. Analysis revealed only one significant two-way interaction, namely 'THREAT*SOCIAL' $F(1,138)=6.36 ; p=.013$, suggesting that the effect of social presence is moderated by threat information. In addition, there was a significant main effect for Gender, $F(1$, $138)=4.233, p=.41$ and pain catastrophizing, $F(1,138)=11.02$; $p=.001$, showing that more pain was reported by female participants, and participants habitually perceive pain as threatening. Exploring the 'THREAT*SOCIAL' interaction further, post-hoc analyses revealed that in the absence of threat, no significant main effect of SOCIAL was found, $F(1,70)=.330, \mathrm{NS}, d=.013$, suggesting 
Table 1

Descriptives (Means and SD) of the main variables for the four experimental conditions.

\begin{tabular}{|c|c|c|c|c|c|c|c|c|c|}
\hline & \multicolumn{4}{|c|}{ No threat $(N=76)$} & \multicolumn{4}{|c|}{ Threat $(N=73)$} & \multirow[t]{3}{*}{$F$-value } \\
\hline & \multicolumn{2}{|c|}{ No social presence $(N=39)$} & \multicolumn{2}{|c|}{ Social presence $(N=37)$} & \multicolumn{2}{|c|}{ No social presence $(N=35)$} & \multicolumn{2}{|c|}{ Social presence $(N=38)$} & \\
\hline & Mean & $S D$ & Mean & $S D$ & Mean & $S D$ & Mean & $S D$ & \\
\hline Age & 32.9 & 11.7 & 33.3 & 10.6 & 27.0 & 7.3 & 30.9 & 11.3 & $2.72^{*}$ \\
\hline PCS2 & 10.8 & 5.8 & 11.1 & 8 & 11.4 & 6.5 & 12.9 & 8.4 & .6 \\
\hline PTP1 & 1.33 & 1.1 & 1.63 & 1.26 & 1.49 & .9 & 1.59 & 1.5 & .46 \\
\hline PTP2 & 1.19 & 1.02 & 1.39 & 1.44 & 1.78 & 1.2 & 1.93 & 1.8 & 2.22 \\
\hline РTP3 & 1.78 & 1.53 & 1.64 & 1.34 & 2.34 & 1.32 & 1.90 & 1.68 & 1.51 \\
\hline P IMM & 4.75 & 2.01 & 4.96 & 1.89 & 5.85 & 1.44 & 4.67 & 2.13 & $2.93^{*}$ \\
\hline P RECOV & 2.68 & 2.12 & 2.96 & 2.00 & 2.99 & 1.60 & 2.42 & 1.83 & .73 \\
\hline F IMM & 167.34 & 101.28 & 200.34 & 118.88 & 181.47 & 117.07 & 145.87 & 78.92 & 1.80 \\
\hline F RECOV & 111.69 & 47.12 & 174.19 & 93.99 & 146.91 & 82.78 & 141.82 & 80.12 & $4.12^{* *}$ \\
\hline
\end{tabular}

${ }^{*} p<.05,{ }^{* *} p<.01$.

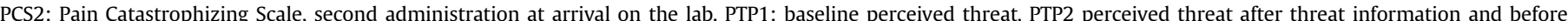

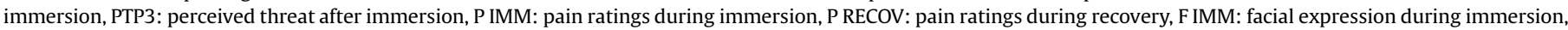
F RECOV: facial expression during recovery. F-values refer to ANOVA testing differences of means among the four conditions.

that social presence does not influence verbal pain report when no threat is induced. In the presence of threat however, a significant difference was found between conditions with and without observer present, $F(1,70)=9.67 ; p=.003, d=1.24$, with significantly more pain reported when the participant was alone as compared to being with an observer. Similarly, in the absence of an observer, there was a significant main THREAT effect, $F(1$, $70)=6265, p=.015, d=.62$ with subjects who received threat information reporting more pain than those receiving neutral information. In contrast, when an observer was present, threat information did not affect pain report, $F(1,70)=1.046, p=.310$, $d=.24$.

Recovery. During the recovery period, neither a significant three-way 'THREAT*SOCIAL*Pain catastrophizing' interaction, $F(1$, $138)=3.365, p=.069$, nor any significant two-way interactions or main effects for THREAT and SOCIAL were found for verbal pain ratings $(p>.106)$. There was however a significant main effect of Gender, $F(1,141)=10.247, p=.002$ and Pain catastrophizing, $F(1,141)=12.648, p=.001$ suggesting that female participants, and participants who habitually interpreted pain catastrophically reported more pain during the recovery than male participants and low pain catastrophizers.

Facial expression. Mean facial expression scores across the four conditions are displayed in Fig. 3, suggesting that subjects in the

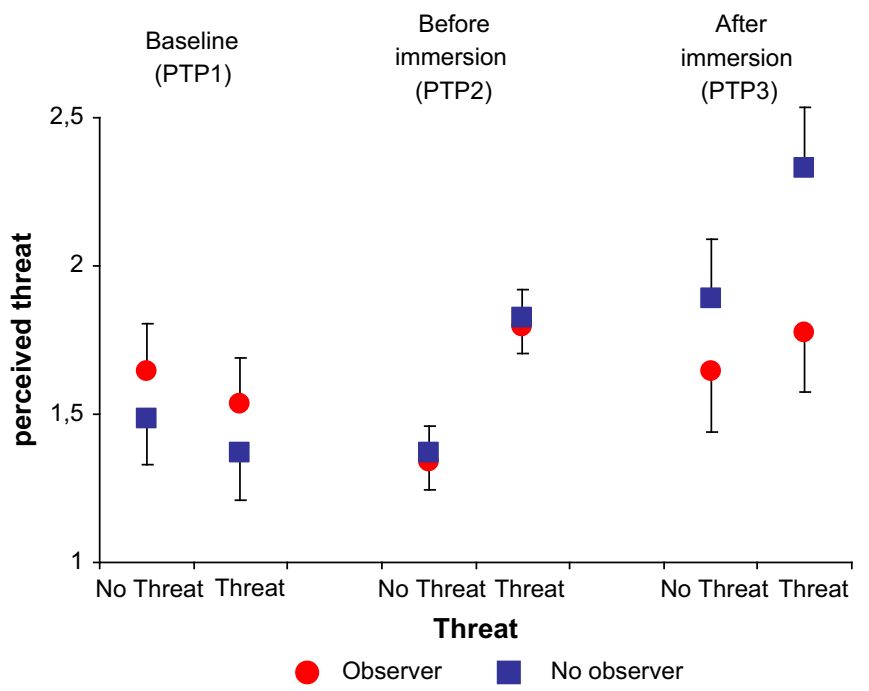

Fig. 1. Estimated marginal means of perceived threat of pain (PTP) scores for the four experimental conditions at baseline (PTP1), just after threat manipulation (and before immersion, PTP2), and just after immersion (PTP3). Error bars refer to SEM. condition with threatening information but with an observer present showed less facial pain expression than those in the three other conditions during immersion. In the recovery period, a different pattern seems to emerge, with social context effects in the no-threat conditions only. Split plot repeated measures ANOVA revealed no TIME*THREAT*SOCIAL interaction, $F(1,141)=.201$, NS, but a significant 'TIME*THREAT' statistical interaction $F(1$, $141)=6.029 ; p=.015$ and 'TIME*SOCIAL' interaction, $F(1$, $141)=5.390 ; p=.022$, suggesting that the influence of threat information and social presence on facial expression during the recovery was different from that during the immersion period. Therefore, analyses were carried out for mean observer ratings during immersion and during the recovery period separately.

Immersion. Results revealed that the three-way 'THREAT"SOCIAL*Pain catastrophizing' interaction did not reach significance, $F(1,141)=2.953, p=.088$, and neither were the predicted two-way 'Pain catastrophizing*SOCIAL' and 'Pain catastrophizing*THREAT' interactions significant $F(1,141)=.53$, NS and $F(1,141)=1.646$, NS respectively. Again, only one significant two-way 'THREAT*SOCIAL' interaction $F(1,141)=4.76 ; p=.031$ was found, showing that also for facial expression, the effect of social presence was moderated by threat and vice versa. In addition, there was a significant main effect of Pain catastrophizing, $F(1,141)=14.206, p<.001$, with high catastrophizers displaying more facial expression than low catastrophizers. A post-hoc analysis of the two-way interaction revealed that in the no-threat condition, no SOCIAL effect $F(1$,

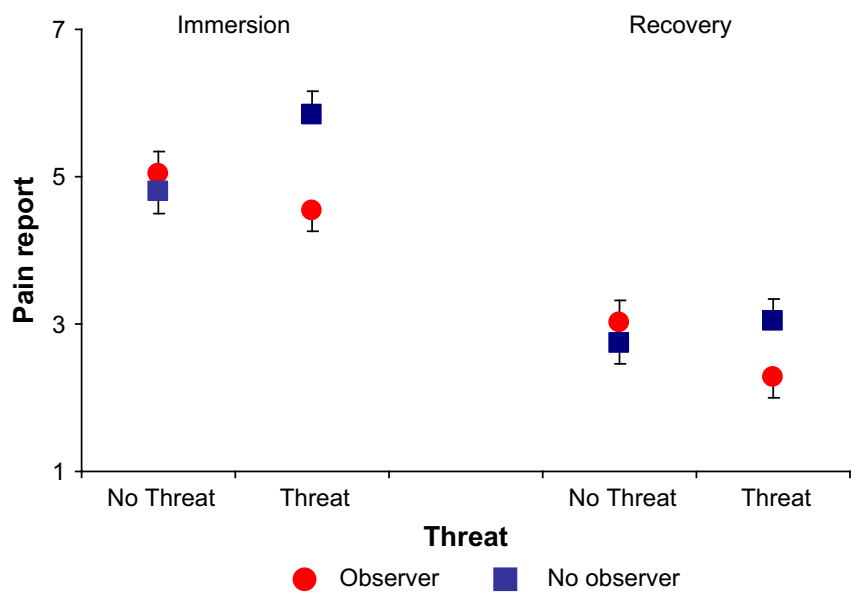

Fig. 2. Estimated marginal means of verbal pain report for the four experimental conditions during cold pressor task immersion and recovery periods. Error bars refer to SEM. 


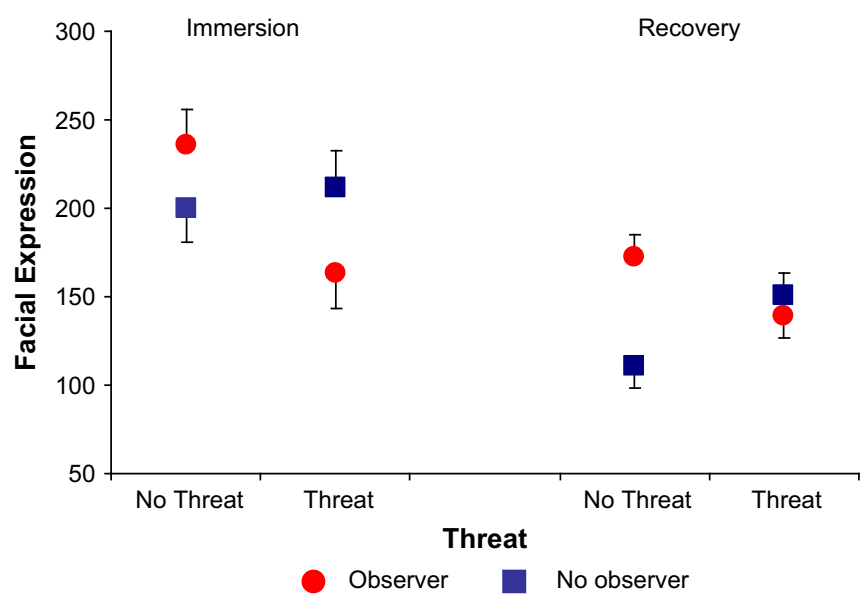

Fig. 3. Estimated marginal means for facial expression scores for the four experimental conditions during cold pressor task immersion and recovery periods. Error bars refer to SEM.

$70)=.91$, NS, $d=.31$ was found. When participants were given threat information, however, ANCOVA revealed a main SOCIAL effect, $F(1,70)=4.21, p=.044, d=.49$, showing that facial expression was significantly lower when an observer is present, which is consistent with the verbal pain report data. In contrast with the results for verbal pain report however, in the absence of an observer there was no main THREAT effect, $F(1,70)=.141$, NS, $d=.09$, suggesting that threat information did not affect facial expression. In the presence of an observer, participants who received threat information showed significantly less facial expression compared to those who did not receive threat information, $F(1,70)=7.828, p=.007, d=.66$.

Recovery. Similar to the immersion period, only a significant two-way 'THREAT*SOCIAL' interaction, $F(1,141)=8.468 ; p=.004$ was found during the recovery period. However, post-hoc analysis of threat effects per level of social presence and vice versa, revealed that participants displayed more facial expression in the presence of an observer than in the absence when no threat information was provided, $F(1,70)=13.851, p<.001, d=.86$. In contrast to the immersion data, there was no social context effect when threat was induced, $F(1,70)=.794$, NS, $d=.21$. Analyses of the threat effect per level of presence revealed that when participants were alone, they showed significantly more facial expression under threat, $F(1$, $70)=4.702, p=.034, d=.53$ than under no threat. When an observer was present, less facial expression was displayed under threat than under no-threat, although this effect did not reach significance, $F(1,70)=2.658, p=.108, d=.38$.

Perceived threat as a mediator between social presence and pain variables

Immersion. Given the significant 'THREAT*SOCIAL' interaction, revealing that social presence had an effect on both verbal pain report and facial expression in the threat information conditions during immersion, and the finding that social presence reduced the perceived threat of pain during immersion, we examined whether perceived threat of pain measured during exposure to the pain stimulus (PTP3) mediated the association between social presence and the pain variables in the threat conditions. Three multiple regression analyses were performed for both pain intensity and facial expression as dependent variables (see Figs. 4 and 5) with SOCIAL as the independent variable. The first analysis (producing the total effect $c+a^{*} b$ ) included the covariates age, gender, baseline perceived threat of pain (PTP2, after threat manipulation but before

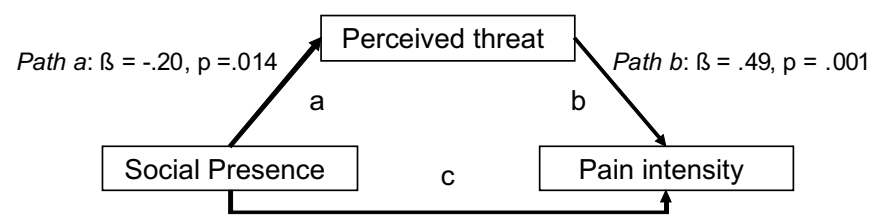

$$
\begin{gathered}
\text { Path } c: \beta=-.24, p=.012 \\
\text { Total effect } c+a^{*} b: \beta=-.34, p=.001
\end{gathered}
$$

Fig. 4. Mediation model for the association between social presence and pain intensity via perceived threat of the cold pressor pain. Standardized Beta's and p-values of individual paths and total effect. Data under threat only conditions during immersion.

immersion and social presence), pain catastrophizing (second administration) with verbal pain ratings (or facial expression) as the dependent variable. The second regression analysis (path a) included the same covariates but now with perceived threat as the dependent variable. The final and third analysis included the same covariates but with perceived threat as an additional covariate (paths b and c). As displayed in Figs. 4 and 5, all of the resulting standardized $\beta$-values met the 'joint significance of paths a and b' criteria as suggested by McKinnon et al. (MacKinnon et al., 2002). Consistent with previous analyses, the standardized $\beta$-values for paths a and $c$ were negative, corroborating the threat reducing and pain reducing effects of social presence. Of interest is that the under no-threat conditions (results not reported here), similar mediation analyses revealed a significant path $\mathrm{b}$ only (perceived threat to pain report and to facial expression).

Recovery. Similar mediation analyses that were carried out for the recovery period, suggest that the effect of social presence on verbal pain report was not mediated by perceived threat in the conditions under threat, with a significant path a (standardized $\beta=-.20, p=.014$ ) but no significant path $\mathrm{b}$ (standardized $\beta=.33$, $p=.054)$. In the recovery period, the verbal report data under nothreat and facial expression data under threat and no-threat conditions did not meet the joint significance criterion as proposed by McKinnon et al., as both paths a and b did not reach statistical significance. The conclusion is that there was no support for mediation of perceived threat on pain expression in the recovery phase.

\section{Discussion}

This study was designed to test whether verbal pain report and facial expression in subjects reporting high pain catastrophizing is enhanced by the presence of an observer, as predicted by the CCM (Sullivan et al., 2001), or by the perceived threat value of pain as predicted by the CAM (Arntz \& Claassens, 2004; Crombez, Vlaeyen, Heuts, \& Lysens, 1999; Severeijns, Vlaeyen, \& Van Den Hout, 2004).

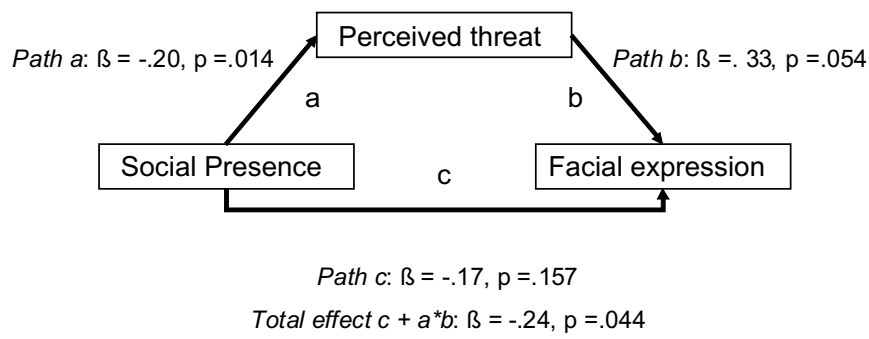

Fig. 5. Mediation model for the association between social presence and facial expression via perceived threat of the cold pressor pain. Standardized Beta's and p-values of individual paths and total effect. Data under threat only conditions during immersion. 
In a $2 \times 2$ factorial design, healthy subjects with varying levels of pain catastrophizing were exposed to a CPT during which both the threat value of the pain and the social context were experimentally manipulated. The manipulation of threat was successful in the sense that subjects in the threat conditions reported significantly more concern regarding the effects of the CPT as compared to those assigned to the no-threat conditions.

The results are not directly in line with either the CCM or the CAM conceptualizations of pain catastrophizing, as we failed to observe the interactions between pain catastrophizing and social presence (CCM prediction), and between pain catastrophizing and threat information (CAM prediction). These observations are also not in line with earlier reports showing that the presence of an observer elicits pain expression in high catastrophizers (Sullivan et al., 2004). Consistent with earlier reports is the main effect of pain catastrophizing on pain expression. Numerous studies have indeed shown that pain catastrophizing is one of the strongest predictors of pain-related outcomes (Turner, Jensen, \& Romano, 2000), probably through bio-behavioural interactions (Campbell \& Edwards, 2009). Recent studies have shown that pain catastrophizing is not only associated with activation of the pain matrix under mild pain exposure (Seminowicz \& Davis, 2006), impaired executive function and inhibitory control (Weissman-Fogel, Sprecher, \& Pud, 2008), and difficulty to disengage from painful stimuli (Crombez, Van Damme, \& Eccleston, 2005; Van Damme, Crombez, \& Eccleston, 2004), but also with dysfunction of endogenous opioid system (Vlaeyen et al., 2004) and release of pro-inflammatory cytokines (Edwards et al., 2008).

A novel and surprising finding, however, is the systematic emergence of a 'THREAT*SOCIAL' interaction, suggesting a different role of the observer depending on whether the pain context is perceived as threatening or not. Closer examination of the immersion data reveals that in a threatening pain context, social presence appears to inhibit pain expression. Following an evolutionary perspective, inhibition of pain expression has survival value in vulnerable situations. However, our findings seem to support the idea that the observer acted as a safety cue, making the pain stimulus less threatening, despite the fact that the observer had minimal verbal exchange with the subjects and was a stranger. Safety signals are conditions that indicate that an aversive stimulus will not occur, and serve to reduce fear, anxiety and avoidance behavior. These may be objects, features of physical environments (Rachman, 1984), or self-generated behaviors (Tang et al., 2007), but also persons can represent a safety signal (Carter, Hollon, Carson, \& Shelton, 1995). The mediation analyses seem to support this conjecture. In the conditions where participants received threat information, social presence reduced perceived threat, which in turn influenced the level of pain intensity and also facial expression, albeit to a somewhat lesser extent. Of interest is that predictors of facial expression were almost similar to those of verbal pain report. Of course, both self-report and non-verbal behaviors are forms of pain behavior, although they may have separate adaptive functions (Williams \& Craig, 2006). A caution is warranted here. From a communicative perspective, facial expression has less function when verbal report is invited at the same time. The facial expression results might have been different had the participants not been asked to provide pain reports.

In the recovery period, a slightly different pattern of results was seen. The 'SOCIAL'THREAT' interaction emerged for facial expression, and not for pain report which was predicted by habitual pain catastrophizing only. Also, differences were observed in the nothreat condition, irrespective of their level of pain catastrophizing, in which participants with an observer present displayed more pain expression compared to participants who were alone. One possible explanation is that these individuals wanted to share non-verbally their emotions and experience of this novel and painful situation with others (Herbette \& Rime, 2004), especially when the other is considered an intimate or part of the in-group (Platow et al., 2007). Note that in our study, the observer was introduced as a 'trainee', whose age fell within the range of the participants. The findings suggest that such a form of social sharing might occur after the novel painful event only and not during the exposure to the pain stimulus itself. In the threat conditions, participants may give attentional priority to the post-immersion sensations in their hand, thereby dismissing information from the social environment. Indeed, there is evidence that pain draws the attention to its location when it is perceived as threatening (Van Damme, Crombez, \& Lorenz, 2007), at the cost of visual cues in the background environment. However, it is unclear why during the recovery period these interactions are not seen for verbal pain report. One explanation might be that participants may have learned that verbal communication with the observer was discouraged, but this possibility warrants further examination.

The findings of this study are not in line with previous studies examining the effects of social presence upon facial expression of pain. In a similar cold pressor task, Sullivan and colleagues (Sullivan et al., 2004) found that high pain catastrophizers displayed communicative behaviors for a longer duration when an observer was present compared to high pain catastrophizers who were alone. An alternative explanation for Sullivan's findings is that the presence of the observer, whose 'ostensible purpose in the room was to record temperature readings from the cold pressor apparatus' (p. 222) has been interpreted by the participants as if there were a potential risk that the water temperature might become too cold, and as a consequence may have increased the threat value of this particular pain context. Unfortunately, the threat value of the CPT was not measured in that study. Our findings corroborated the findings by Jackson et al (Jackson et al., 2005) who found that cold pressor pain tolerance was associated with induced threat through the mediation of perceived threat, and also fit within the cognitive model of emotional disorders (Mathews \& MacLeod, 1994) and the safety signal theory (Lohr et al., 2007; Rachman, 1984; Seligman \& Binik, 1977).

There are several limitations to this study, which may be addressed in future studies. First, because we included a healthy and relatively young adult sample, these findings do not necessarily generalize to clinical samples and other age groups. The study also did not assess other influences that may moderate the effects of social presence on pain such as the gender of both subjects and observer gender. Another limitation is that we were only able to perform a subsidiary mediation analyses to further test the CAM, but not CCM. In addition, the setting was quite artificial in that the observer was instructed not to engage in any conversation with the participants, which limited the possibility of examining whether high catastrophizers were indeed eliciting support and empathy through their pain expression as would be predicted by CCM. Moreover, some of the explanations are rather speculative and warrant further controlled examination. An intriguing question is whether social context may not only act as safety cues, but also as danger cues, thereby possibly increasing the perceived threat of pain. Future studies might examine the effects of several characteristics of the observer, for example observers that are cooperative versus competitive, or observers who are fearful of pain themselves versus non-fearful observers. We also note that different predictions can be derived from other conceptualizations. For example, an evolutionary perspective (Williams, 2002) suggests that the presence of a hostile stranger, or member of social out-group will increase threat, and thus suppress pain in contrast to increase pain expression in the presence of others as predicted by the CAM. We are currently preparing a study examining whether social threat 
influences the threat value of pain, and under which conditions they increase or suppress pain expression. Finally, and as in most laboratory studies, the manipulation of threat produced relatively weak increased in concerns about the pain stimulus. However, despite these small effects, we were able to show the role of perceived threat as a mediator between social presence and pain outcomes.

In sum, this study revealed pain catastrophizing did not moderate the effects of social presence and threat information on pain expression, as was predicted by CCM and CAM, but was associated with increased pain expression independently of these situational factors. These results suggest that the dynamic interactions between threat appraisals and social context variables might be at least as important in the prediction of pain expression as the more stable individual characteristics such as pain catastrophizing.

\section{Acknowledgements}

We are grateful to Ger van Wunnik, Loek Peters and André van der Zanden for technical assistance during video recordings of facial expressions and to Annemarie Dautzenberg for her valuable assistance in the scoring of pain behavior. We also wish to thank two anonymous reviewers for their inspiring reflections and suggestions. Participation of Johan W.S. Vlaeyen was supported by the NWO Social Sciences Research Council of the Netherlands, Grant No. 453-04-003, and an Odysseus Grant by the Fund for Scientific Research - Flanders (FWO).

\section{References}

Arntz, A., \& Claassens, L. (2004). The meaning of pain influences its experienced intensity. Pain, 109(1-2), 20-25.

Baron, R. M., \& Kenny, D. A. (1986). The moderator-mediator variable distinction in social psychological research: conceptual, strategic, and statistical considerations. Journal of Personality and Social Psychology, 51(6), 1173-1182.

Campbell, C. M., \& Edwards, R. R. (2009). Mind-body interactions in pain: the neurophysiology of anxious and catastrophic pain-related thoughts. Translational Research: The Journal of Laboratory and Clinical Medicine, 153(3), 97-101.

Carter, M. M., Hollon, S. D., Carson, R., \& Shelton, R. C. (1995). Effects of a safe person on induced distress following a biological challenge in panic disorder with agoraphobia. Journal of Abnormal Psychology, 104(1), 156-163.

Chambers, C. T., Cassidy, K. L., McGrath, P. J., Gilbert, C. A., \& Craig, K. D. (1996). Child Facial Coding System. Revised Manual. Halifax, Nova Scotia.

Craig, K. D. (1975). Social modelling determinants of pain processes. Pain, 1(4), 375-378.

Craig, K. D. (1978). Social modeling influences on pain. In R. A. Sternbach (Ed.), The psychology of pain (pp. 73-111). New York: Raven Press.

Crombez, G., Van Damme, S., \& Eccleston, C. (2005). Hypervigilance to pain: an experimental and clinical analysis. Pain, 116(1-2), 4-7.

Crombez, G., Vlaeyen, J. W., Heuts, P. H., \& Lysens, R. (1999). Pain-related fear is more disabling than pain itself: evidence on the role of pain-related fear in chronic back pain disability. Pain, 80(1-2), 329-339.

Eccleston, C., \& Crombez, G. (1999). Pain demands attention: a cognitive-affective model of the interruptive function of pain. Psychological Bulletin, 125(3) 356-366.

Edwards, R. R., Kronfli, T., Haythornthwaite, J. A., Smith, M. T., McGuire, L., \& Page, G. G. (2008). Association of catastrophizing with interleukin-6 responses to acute pain. Pain, 140(1), 135-144.

Ekman, P., \& Friesen, W. V. (1978). Facial Action Coding System: A technique for the measurement of facial movement. Palo Alto, CA: Consulting Psychologists Press.

Ekman, P., \& Rosenberg, E. L. (1997). What the face reveals. Basic and applied studies of spontaneous expression using the Facial Action Coding System (FACS). New York: Oxford: Oxford University Press.

Flor, H., Knost, B., \& Birbaumer, N. (2002). The role of operant conditioning in chronic pain: an experimental investigation. Pain, 95(1-2), 111-118.

Fordyce, W. E. (1976). Behavioral methods for chronic pain and illness. St. Louis: Mosby

Hadjistavropoulos, T., \& Craig, K. D. (2002). A theoretical framework for understanding self-report and observational measures of pain: a communications model. Behaviour Research and Therapy, 40(5), 551-570.

Herbette, G., \& Rime, B. (2004). Verbalization of emotion in chronic pain patients and their psychological adjustment. Journal of Health Psychology, 9(5), 661-676.
Jackson, T., Pope, L., Nagasaka, T., Fritch, A., Iezzi, T., \& Chen, H. (2005). The impact of threatening information about pain on coping and pain tolerance. British Journal of Health Psychology, 10(Pt 3), 441-451.

Jolliffe, C. D., \& Nicholas, M. K. (2004). Verbally reinforcing pain reports: an experimental test of the operant model of chronic pain. Pain, 107(1-2), 167-175.

Keefe, F. J., \& Porter, L. (2007). Pain catastrophizing in the context of satisfaction with spousal responses: new perspectives and new opportunities. Pain, 131(1-2), 1-2.

Lackner, J. M., \& Gurtman, M. B. (2004). Pain catastrophizing and interpersonal problems: a circumplex analysis of the communal coping model. Pain, 110(3), 597-604.

Leeuw, M., Goossens, M. E., van Breukelen, G. J., de Jong, J. R., Heuts, P. H., Smeets, R. J., et al. (2008). Exposure in vivo versus operant graded activity in chronic low back pain patients: results of a randomized controlled trial. Pain, 138(1), 192-207.

Lethem, J., Slade, P. D., Troup, J. D., \& Bentley, G. (1983). Outline of a fear-avoidance model of exaggerated pain perception-I. Behaviour Research and Therapy, 21(4), 401-408.

Lohr, J. M., Olatunji, B. O., \& Sawchuk, C. N. (2007). A functional analysis of danger and safety signals in anxiety disorders. Clinical Psychology Review, 27(1), 114-126.

Lousberg, R., Schmidt, A. J., \& Groenman, N. H. (1992). The relationship between spouse solicitousness and pain behavior: searching for more experimental evidence. Pain, 51(1), 75-79.

MacKinnon, D. P., Lockwood, C. M., Hoffman, J. M., West, S. G., \& Sheets, V. (2002). A comparison of methods to test mediation and other intervening variable effects. Psychological Methods, 7, 83-104.

Mathews, A., \& MacLeod, C. (1994). Cognitive approaches to emotion and emotional disorders. Annual Review of Psychology, 45, 25-50.

Platow, M. J., Voudouris, N. J., Coulson, M., Gilford, N., Jamieson, R., Najdovski, L., et al. (2007). In-group reassurance in a pain setting produces lower levels of physiological arousal: direct support for a self-categorization analysis of social influence. European Journal of Social Psychology, 37, 649-660.

Rachman, S. (1984). Agoraphobia-a safety-signal perspective. Behaviour Research and Therapy, 22(1), 59-70.

Seligman, M., \& Binik, Y. (1977). The safety signal hypothesis. In H. Davis, \& H. M. B. Hurwitz (Eds.), Pavlovian-operant interactions (pp. 165-180). Hillsdale, NJ: Lawrence Erlbaum.

Seminowicz, D. A., \& Davis, K. D. (2006). Cortical responses to pain in healthy individuals depends on pain catastrophizing. Pain, 120(3), 297-306.

Severeijns, R., Vlaeyen, J. W., \& Van Den Hout, M. A. (2004). Do we need a communal coping model of pain catastrophizing? An alternative explanation. Pain, 111(3), 226-229.

Sullivan, M. J., Adams, H., \& Sullivan, M. E. (2004). Communicative dimensions of pain catastrophizing: social cueing effects on pain behaviour and coping. Pain, 107(3), 220-226.

Sullivan, M. J., Bishop, S. R., \& Pivik, J. (1995). The pain catastrophizing scale: development and validation. Psychological Assessment, 7, 524-532.

Sullivan, M. J., Thorn, B., Haythornthwaite, J. A., Keefe, F., Martin, M., Bradley, L. A., et al. (2001). Theoretical perspectives on the relation between catastrophizing and pain. The Clinical Journal of Pain, 17(1), 52-64.

Tait, R. C. (2007). The social context of pain management. Pain Medicine, 8(1), 1-2.

Tang, N. K., Salkovskis, P. M., Poplavskaya, E., Wright, K. J., Hanna, M., \& Hester, J. (2007). Increased use of safety-seeking behaviors in chronic back pain patients with high health anxiety. Behaviour Research and Therapy, 45(12), 2821-2835.

Thorn, B. E., Boothby, J. L., \& Sullivan, M. E. (2002). Targeted treatment of catastrophizing for the management of chronic pain. Cognitive and Behavioral Practice, 9, 127-138.

Thorn, B. E., Keefe, F. J., \& Anderson, T. (2004). The communal coping model and interpersonal context: problems or process? Pain, 110(3), 505-507.

Thorn, B. E., Pence, L. B., Ward, L. C., Kilgo, G., Clements, K. L., Cross, T. H., et al. (2007). A randomized clinical trial of targeted cognitive behavioral treatment to reduce catastrophizing in chronic headache sufferers. Journal of Pain, 8(12), 938-949.

Thorn, B. E., Ward, L. C., Sullivan, M. J., \& Boothby, J. L. (2003). Communal coping model of catastrophizing: conceptual model building. Pain, 106(1-2), 1-2.

Turkat, I. D., \& Guise, B. J. (1983). The effects of vicarious experience and stimulus intensity on pain termination and work avoidance. Behaviour Research and Therapy, 21(3), 241-245.

Turner, J. A., Jensen, M. P., \& Romano, J. M. (2000). Do beliefs, coping, and catastrophizing independently predict functioning in patients with chronic pain? Pain, 85(1-2), 115-125.

Van Damme, S., Crombez, G., Bijttebier, P., Goubert, L., \& Van Houdenhove, B. (2002). A confirmatory factor analysis of the pain catastrophizing scale: invariant factor structure across clinical and non-clinical populations. Pain, 96(3), 319-324.

Van Damme, S., Crombez, G., \& Eccleston, C. (2004). Disengagement from pain: the role of catastrophic thinking about pain. Pain, 107(1-2), 70-76.

Van Damme, S., Crombez, G., \& Lorenz, J. (2007). Pain draws visual attention to its location: experimental evidence for a threat-related bias. Journal of Pain, 8(12), 976-982.

Van Damme, S., Crombez, G., Van Nieuwenborgh-De Wever, K., \& Goubert, L. (2008). Is distraction less effective when pain is threatening? An experimental investigation with the cold pressor task. European Journal of Pain, 12(1), 60-67.

Vervoort, T., Goubert, L., Eccleston, C., Verhoeven, K., De Clercq, A., Buysse, A., et al. (2008). The effects of parental presence upon the facial expression of 
pain: the moderating role of child pain catastrophizing. Pain, 138(2), 277-285.

Vlaeyen, J. W., de Jong, J., Geilen, M., Heuts, P. H., \& van Breukelen, G. (2001). Graded exposure in vivo in the treatment of pain-related fear: a replicated single-case experimental design in four patients with chronic low back pain. Behaviour Research and Therapy, 39(2), 151-166.

Vlaeyen, J. W., Kole-Snijders, A. M., Boeren, R. G., \& van Eek, H. (1995). Fear of movement/(re)injury in chronic low back pain and its relation to behavioral performance. Pain, 62(3), 363-372.

Vlaeyen, J. W. S., \& Linton, S. J. (2000). Fear-avoidance and its consequences in chronic musculoskeletal pain: a state of the art. Pain, 85(3), 317-332.
Vlaeyen, J. W., Timmermans, C., Rodriguez, L. M., Crombez, G., Van Horne, W. Ayers, G. M., et al. (2004). Catastrophic thinking about pain increases discomfort during internal atrial cardioversion. Journal of Psychosomatic Research, 56(1), 139-144.

Weissman-Fogel, I., Sprecher, E., \& Pud, D. (2008). Effects of catastrophizing on pain perception and pain modulation. Experimental Brain Research, 186(1) 79-85.

Williams, A. C. (2002). Facial expression of pain: an evolutionary account. Behavioral and Brain Sciences, 25(4), 439-455, discussion 455-488.

Williams, A. C., \& Craig, K. D. (2006). A science of pain expression? Pain, 125(3), 202-203. 